\title{
Saúde pública: biotecnociência, biopolítica e bioética
}

\author{
Public health: biotechnoscience, biopolitics, and bioethics \\ Fermin Roland Schramm $\mathbf{1}$
}

DOI: 10.1590/0103-110420195712

RESUMO O campo complexo da saúde pública pode ser visto como sendo atravessado pela seguinte polaridade: a) uma tendência totalizante de controle da sociedade tanto do ponto de vista biológico como econômico; b) uma tendência à individualização das práticas da medicina e da saúde pública baseada na liberdade e na responsabilização dos indivíduos pela sua saúde. Ademais, devido ao fato de o campo da saúde corresponder às atividades da biotecnociência e da biopolítica, e ser, portanto, atravessado por conflitos de interesses e de valores, entra em campo a bioética, cujo escopo principal no campo da saúde e do bem-estar individual e coletivo consiste em detectar, analisar e avaliar tais conflitos, propondo soluções que impliquem alguma forma de convergência entre agentes e pacientes morais envolvidos, e que vise, em última instância, à qualidade de vida dos afetados pelas políticas públicas e pela incorporação das ferramentas da biotecnociência.

PALAVRAS-CHAVE Bioética. Política. Biotecnologia. Saúde pública.

ABSTRACT The complex field of public health can be seen as crossed by the following polarity: a) a totalizing tendency to control society, both biologically and economically; b) a tendency towards individualization of medical and public health practices, based on individuals' freedom and accountability for their own health. Furthermore, since the field of health has to do with biotechnoscientific and biopolitical activities, and is thus permeated by conflicts of interests and values, bioethics enters the scene because its main scope in the field of health and individual and collective welfare consists of detecting, analyzing, and assessing such conflicts, proposing solutions that involve some form of convergence between moral agents and patients, ultimately aiming at quality of life of those affected by public policies and the incorporation of the tools of biotechnoscience.

KEYWORDS Bioethics. Politics. Biotechnoscience. Public health.

1 Fundação Oswaldo Cruz (Fiocruz), Escola Nacional de Saúde Pública Sergio Arouca (Ensp) - Rio de Janeiro (RJ), Brasil. rolandschram@yahoo.com.br 


\section{Introdução}

A saúde pública pode ser pensada como um campo atravessado por uma polaridade constituída, por um lado, pela medicina social baseada na ideia de um controle da sociedade "finalizado ao máximo desenvolvimento de suas potencialidades vitais" e constituído por "intervenções autoritárias", tendo em vista a proteção de "populações privilegiadas" e adotando "políticas de assistência pública finalizadas ao controle e à normalização das classes desfavorecidas", e, por outro, por formas de "resistência popular" como as "insurreições anti-médicas" focalizadas sobre questões referentes "à vida e à morte, [a]o direito de adoecer e eventualmente de se curar de acordo com a própria vontade' do doente"1(270).

No entanto, tal 'medicalização da saúde' foi vista também como uma espécie de 'religião secular' do mundo moderno ${ }^{2}$ ou, anteriormente, de acordo com Foucault, como objeto para a "luta política contra os excessos da governamentalidade médica"’(270). Essa é a razão pela qual a história da saúde pública não poderia ser separada dos movimentos 'anti-higienistas' que entrelaçaram com o liberalismo relações complexas e diversas de acordo com os contextos nacionais e regionais $\mathbf{1}$. De fato, tais movimentos possuem relações contraditórias com o próprio liberalismo, que, por sua vez, é atravessado por 'paradoxos' como aquele que se refere à 'promoção' da saúde e, ao mesmo tempo, à 'recusa' da saúde pública por considerar que a 'governamentalização' da medicina e de suas práticas pelo Estado - que passa a ser visto por Foucault como Estado governamental - é um dispositivo questionável por ser autoritário e, em alguns casos, totalitário ${ }^{3}$, o que pode ser visto como uma "reconfiguração da relação entre a saúde pública e a questão social’’(275) constituída pela

convergência entre uma nova estatística social - a epidemiologia do risco sanitário - e uma nova consciência das desigualdades sociais provocadas pelo aumento da precariedade e o desmantelamento do welfare ${ }^{\mathbf{1 ( 2 7 5 )}}$.
É nesse contexto que podemos situar a biotecnociência e a biopolítica, cujas práticas e políticas no campo da saúde pública são abordadas pela vertente da bioética sanitária desde os anos 1990 na América Latina e, em particular, no Brasil ${ }^{4}$. Em nossa abordagem, tentaremos destacar as características que consideramos pertinentes da biotecnociência, entendida como a forma de ciência associada à técnica e aplicada aos seres e sistemas vivos, e tendo em vista a criação e produção de bens e serviços que dizem respeito à saúde e ao bem-estar de indivíduos e populações de humanos. Contudo, no campo da saúde pública, as ferramentas da biotecnociência (mais conhecidas como biotecnologias) possuem vínculos estreitos com a biopolítica, entendida, a partir de Foucault, como a dimensão de exercício do poder (chamado biopoder) que transforma a espécie dos seres humanos em objetos de uma estratégia política geral e consistente na aplicação das disciplinas ao corpo-organismo e na regulação do corpo-espécie da população ${ }^{5}$. Por fim, devido ao fato de o campo da saúde ter a ver com as práticas da biotecnociência e da biopolítica, e ser, portanto, atravessado por conflitos de interesses e de valores que permeiam suas práticas, entra em campo a forma de ética aplicada conhecida como bioética, cujo escopo principal no âmbito da saúde e do bem-estar individual e coletivo consiste em detectar, analisar e avaliar tais conflitos, propondo soluções que constituam alguma forma de convergência entre agentes e pacientes morais envolvidos e que visem, em última instância, à qualidade de vida dos afetados pelas políticas públicas e pela incorporação das ferramentas adequadas da biotecnociência.

\section{O campo complexo da saúde pública}

O termo 'saúde pública' se refere a um campo complexo formado por um conjunto de práticas e serviços que têm o objetivo de prevenir e combater doenças e moléstias, tentando evitar 
cenários que coloquem em risco a saúde e o bem-estar das populações, e cabendo, em princípio, ao Estado que se queira legítimo assegurar serviços e políticas que promovam a saúde e o bem-estar de seus cidadãos. Nesse sentido, a saúde pública pode ser vista como uma disciplina dinâmica cujo objeto é, em tese, a melhora permanente da saúde da população, mas que implica se dar conta que

definir o que é a saúde pública não é tarefa fácil [pois] não possuímos uma ideia clara do que é a saúde das populações [visto que] o conceito de saúde só se aplica, em todo rigor, a pessoas, [ademais, não sabemos responder à pergunta] a saúde de um grupo ou de uma população é boa ou má?6(1330-31).

Esta pergunta remete àquilo que o sanitarista Giovanni Berlinguer ${ }^{\text {7(19-24) }}$ chamou de "duas utopias": a primeira referida à definição de saúde dada pela OMS, em 1948, quando a saúde foi pensada como "um estado de completo bem-estar físico, mental e social”, e que pretendia superar a ideia de saúde como mera ausência de doença; a segunda formulada em 1978 também pela OMS, que defendia "a saúde para todos no ano 2000", mas que, em 1991, reconheceu "um substancial falimento deste objetivo" porque a efetiva "distribuição da saúde (e das possibilidades de vida) não responde ao objetivo para todos".

Em particular, a saúde pública pode ser vista atualmente como uma "tecnologia científico-política em perene tensão entre uma mecânica totalizante e uma mecânica individualizante"1(275), podendo ser caracterizada pelo seguinte movimento:

mais ela se torna uma prática de condução de si mesmos através de si mesmos e uma tecnologia de subjetivação, mais sua dimensão política tende a coincidir com o dado biológico sobre o qual ela insiste. Em outros termos, a saúde pública se dissolve na saúde dos indi-

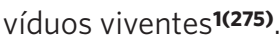

Todavia, isso pode ser visto como problemático porque "uma subjetivação fundada numa imagem positiva da saúde" que motive os indivíduos a se tornarem "os managers de si mesmos adotando um estilo de vida que faça a economia dos comportamentos de risco" pode estar acompanhada de uma "desresponsabilização do Estado em matéria de assistência social", o que seria, por certo, substituído por uma "progressiva responsabilização ética dos indivíduos na gestão de seu patrimônio biológico e de sua saúde", podendo-se, por isso, falar em "faces contraditórias e complementares de um novo 'direito à saúde"'”(276).

É nesse contexto complexo e dinâmico que podemos inscrever a biotecnociência, a biopolítica e a bioética, a respeito das quais propomos uma análise dos significados contidos nelas, e relacionando-as entre si para tentar ver se é possível chegar a algum tipo de síntese que explique o sentido do conjunto. Em particular, em nossa abordagem destacamos inicialmente as características pertinentes da biotecnociência, entendida como uma forma de ciência entrelaçada com a técnica e aplicada aos seres e sistemas vivos, e tendo em vista a criação e produção de bens e serviços que dizem respeito, em especial, à saúde e ao bem-estar de indivíduos e populações de humanos. Entretanto, no campo da saúde pública, as ferramentas da biotecnociência (também conhecidas como biotecnologias) possuem vínculos estreitos com a biopolítica, entendida, a partir de Foucault ${ }^{5}$, como a dimensão de exercício do poder (chamado biopoder) que transforma a espécie dos seres humanos em objetos de uma estratégia política geral (ou biopolítica) e consistente na aplicação das disciplinas ao corpo-organismo e na regulação do corpo-espécie da população. Por fim, devido ao fato do campo da saúde ter a ver com as práticas da biotecnociência e com os dispositivos da biopolítica, e podendo ser atravessado por conflitos de interesses e de valores entre os atores envolvidos, entra em campo a forma de saber-fazer conhecida como bioética, cujo escopo principal consiste em detectar, analisar e avaliar tais conflitos, 
propondo - quando for possível - soluções que impliquem alguma forma de convergência entre agentes e pacientes morais envolvidos, e que vise, em última instância, à qualidade de vida dos afetados pelas políticas públicas e pela incorporação das ferramentas da biotecnociência.

\section{O paradigma da biotecnociência}

'Biotecnociência' é um neologismo criado para indicar uma relação entre ciência, técnica e vida, que pretende indicar o campo de atuação atual da tecnociência aplicada aos seres e sistemas vivos. Em outros termos, a biotecnociência representa um novo paradigma que emerge no campo dos saberes graças aos avanços da tecnociência aplicada aos sistemas e seres vivos.

O neologismo tem um parentesco com outro neologismo: "tecnociência", que designa "a natureza essencialmente operativa" da ciência moderna e cujo "núcleo duro [é] tecnomatemático", podendo-se dizer que "hoje em dia, os polos teórico e técnico da atividade científica estão indissoluvelmente emaranhados"8(11-14). Por isso, a tecnociência não deveria ser vista como uma ciência específica, mas como uma característica das ciências em geral no mundo contemporâneo, que remete ao conceito de saber-fazer e que indica os procedimentos concretos das várias ciências experimentais, com destaque nas suas finalidades pragmáticas. Em outros termos, a tecnociência considera a técnica como motor da pesquisa e parece ser guiada pelo imperativo técnico "se algo pode ser feito deve ser feito", que, por sua vez, pode ser criticado quando considerado "amoral"9(772). De fato, a competência de desenvolver novas tecnologias é o resultado da aliança entre uma nova concepção de ciência dos cientistas, distinta da ciência logoteórica antiga (separada da technê) e a capacidade técnica e operacional, sobretudo dos engenheiros, chamada tecnociência, isto é, a "ciência da ação ou da intervenção eficazes no universo [que] permite prever e produzir" ou "ciência aplicada"; o que a tornaria "impura, fazendo-a perder a sua bondade ou a sua inocência essenciais", visto que a "aplicação técnica da ciência será, com efeito, boa ou má”'10(461), razão pela qual poderá ser avaliada pela bioética.

Assim, a biotecnociência pode ser vista como um novo paradigma que consiste em um

[...] padrão de competência em adaptar [a] 'natureza' humana aos desejos e projetos humanos [...] para aliviar o sofrimento, prevenir doenças, melhorar as condições de vida, programar a qualidade de vida dos descendentes, programar o fim da vida [e] em superar os limites impostos pela dimensão orgânica à condição humana [graças à] reprogramação da própria natureza humana. [Trata-se] essencialmente [de uma] recusa dos limites impostos pela evolução biológican1(114-115).

Dito de maneira mais sintética: trata-se de um

[...] conjunto de ferramentas teóricas, técnicas, industriais e institucionais que visam entender e transformar seres e processos vivos, de acordo com necessidades/desejos de saúde [...] visando [o] bem-estar de indivíduos e populações humanas [e não humanas] ${ }^{\mathbf{1 2 ( 2 1 )} \text {. }}$

Se considerarmos as implicações morais das práticas biotecnocientíficas, surge o paradigma bioético, entendido como "campo multidisciplinar onde todas as ciências da natureza e do homem, o direito, a teologia e a filosofia intervêm"10(463). Na prática, o desenvolvimento tecnológico implica 'rupturas' de hábitos e constitui, portanto, "um dos determinantes chaves da evolução das técnicas, da melhora do nível de vida, e, consequentemente, do crescimento"13(623); mas é também um divisor de águas entre

as trajetórias das economias desenvolvidas, caracterizadas por [uma] inovação permanente e [aquelas] dos países que continuam a estar submetidos à rotina e às práticas

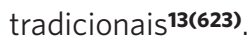


No entanto, tais 'rupturas' se dão num contexto de incerteza, pois são imprevisíveis e só podemos constatar seus efeitos a posteriori, $\mathrm{e}$ seus riscos só podem ser calculados probabilisticamente em cada novo caso de inovação e desenvolvimento tecnológico específico.

Em particular, um dos aspectos problemáticos da vigência do paradigma biotecnocientífico se refere à transformação do humano, indicada pelos termos transhumanismo e posthumanismo, e referidos às transformações do humano graças ao uso, inter alia, da biotecnociência, particularmente da biomedicina. Trata-se, de fato, de uma 'utopia' que visa à melhora ou ao aumento das capacidades (ou competências) do ser humano e que foi definida como 'progressismo prometeico de melhora da natureza humana', criticado pelos 'bioconservadores' como Jürgen Habermas e preocupados com 'os riscos para a saúde e das consequências para a justiça social'; mas que é defendida pelos 'pensadores liberais' como John Harris, que consideram que a decisão de utilizar as tecnologias de melhora

pertence amplamente à liberdade humana; [e os] transhumanistas [que são] tecnofílicos [por defender a] transformação do ser humano pela tecnociência, [ou seja, por defender] um uso racional das biotecnologias ${ }^{\mathbf{1 4}(7-8)}$.

Tal competência biotecnocientífica de aprimoramento do ser humano é abordada, em particular, por Günther Anders 15(3-14), que a considera, corretamente, como uma característica da nossa época, a qual seria aquela do homo creator, termo que o autor adotou em sua obra 'O homem é antiquado', na qual propõe uma

[...] antropologia filosófica [para a] era da tecnocracia, [a qual seria] definitiva e irrevogável, [pois] a técnica se tornou o sujeito da história [ao passo que] nós somos somente co-históricos; [ou seja, possuímos uma nova identidade que adquirimos] porque a capacidade de mudar nosso mundo [e] a nós mesmos, pertence paradoxalmente à nossa natureza, [o que teria implicado em] transformar o homem em homo creator [...] transformando a si mesmo em matéria prima, isto é em homo matéria.

Particularmente, a 'reprogramação' da 'natureza humana' indicada pelo termo homo creator pode ser vista como sendo uma das tarefas implicadas pela utilização das ferramentas e dos dispositivos da biotecnociência; fato que pode ser visto como implicando a necessidade de uma avaliação bioética dos aspectos morais envolvidos. Com efeito, de acordo com John Harris ${ }^{16(1)}$

[...] a rapidez do progresso tecnológico, em particular biotecnológico, tem confundido nossas categorias morais [e] hoje podemos transcender os limites de espécies particulares e combinar virtudes (e vícios) de espécies diferentes, programando novos atributos nunca antes encontrados em nenhuma espécie.

Por isso, para o autor não seria exagerado dizer que a humanidade se encontra atualmente em uma encruzilhada onde

[...] pela primeira vez [ela] pode formar seu próprio destino, decidindo não só que tipo de mundo deseja criar e habitar, mas também de como queremos ser, [mudando] a natureza dos seres humanos; e [Harris termina perguntando] devemos celebrar a ingenuidade e a imaginação dos biotecnologistas que tornaram isso possível ou, ao contrário, limitar e controlar suas atividades?17(2).

Uma questão bastante debatida nos últimos tempos, que tem a ver com a junção (ou aliança) entre 'homem novo', 'pós-humano', 'transumano' e biotecnociência diz respeito à prática do 'aprimoramento humano' (human enhancement), que consiste em reforçar a competência biológica (biological enhancement) e moral (moral enhancement) humana para poder sobreviver e se adaptar a um mundo em rápida transformação.

Em uma avaliação recente, os transhumanistas representariam um "progressismo 
prometeico" consistente em tentar "melhorar a natureza humana pela tecnologia", defendendo, assim, uma "utopia tecnocientífica que possui o objetivo de melhorar o ser humano" e que se apoiaria nos "novos poderes da biomedicina" que emergem da "biomedicina do século XXI", o que representaria uma "mudança de paradigma na prática médica"13(8).

Para Julian Savulescu e Ingmar Persson 17, a questão do "aprimoramento moral" é importante se considerarmos os rápidos avanços de ciência e tecnologia, pois

[...] o conhecimento da biologia humana, em especial da genética e da neurobiologia [permite afetar] as bases fisiológicas da motivação humana, quer por meio da aplicação de drogas, por seleção genética ou engenharia, ou pela utilização de dispositivos externos que afetem o cérebro ou o processo de aprendizagem.

Em especial, para os dois autores, deveríamos utilizar a prática do aprimoramento para superar a incompetência psicológica e moral que colocam em perigo a espécie humana, visto que

[...] os riscos que enfrentamos são tão graves que é imperativo explorar todas as possibilidades de aprimoramento moral [...] não para substituir a tradicional educação moral, mas, sim, para complementá-la [pois] temos transformado radicalmente os nossos ambientes sociais e naturais pela tecnologia [mas] a nossa competência moral manteve-se praticamente inalterada17.

Em suma, deveríamos "considerar a possibilidade de aplicar a tecnologia à nossa própria natureza [para] aprimorar nossa capacidade de criar benefícios ou, pelo menos, para evitar danos"17.

\section{O surgimento da biopolítica}

A saúde pública e a biotecnociência possuem também uma relação com a biopolítica, termo com o qual Michel Foucault indicou uma dimensão importante do exercício do poder, que o autor chamou de 'biopoder' 5 e que se refere às situações em que a espécie humana se torna objeto de uma estratégia política aplicada ao governo dos homens, que Foucault considerou diferente da tradicional soberania ${ }^{3}$. Em particular, a biopolítica tem a ver com as práticas governamentais que visam garantir a saúde das populações pelo controle da fecundidade, da longevidade e da mortalidade, e tentando garantir tais atividades de controle tanto no nível individual (ou 'corpo organismo') como populacional (ou 'corpo espécie') ${ }^{\mathbf{1 8}}$.

Nas palavras do próprio Foucault19(818): devemos entender

[...] por 'biopolítica' a maneira pela qual, a partir do século XVIII, se buscou racionalizar os problemas colocados para a prática governamental pelos fenômenos próprios de um conjunto de viventes enquanto população: saúde, higiene, natalidade, longevidade, raça.

Ou seja, para Foucault19(213-216)

[...] um dos fenômenos fundamentais do século XIX tem sido [e] é que o poder tenha tomado a seu cargo a vida, numa perspectiva [que podemos] chamar assistencial. Trata-se [de] uma tomada de poder sobre o homem como ser vivo, de uma espécie de estatização do biológico, [...] algo que não é mais uma anátomo-política do corpo humano, mas que chamaria uma 'biopolítica' da espécie humana.

De fato, para Foucault, a palavra 'biopolítica' pode referir-se tanto às políticas contemporâneas de assistência e welfare (como as políticas de saúde) quanto àquelas que concebem o Estado como um organismo. De acordo com a filósofa Laura Bazzicalupo 21(3-5), para Foucault, a biopolítica tem a ver tanto com formas de dominação pelo biopoder como com a própria democracia, que "desde sua origem incorpora um elemento biológico", sendo que o "governo da vida" teria a ver com 
"uma profunda mudança do poder, que agarra diretamente a vida, modificando-a", o que nos introduziria no "reino da necessidade" onde se situa "aquele elemento biológico, corpóreo, aquela vulnerabilidade que nos reúne" e que pode "gerar possibilidades positivas de vida e/ou arriscadas dinâmicas de poder".

Em sua avaliação do trabalho de Foucault, a autora considera que a 'intuição de Foucault' constitui um "ponto de partida" para a reflexão atual sobre biopolítica e governança; ou seja, sobre 'uma série de práticas de gestão das vidas humanas' que implicam um 'projeto de melhoria sócio-política, que se coloca na perspectiva da biologia e da economia, descreve o homem para objetivá-lo, seja como ser biológico vivente seja como ator produtivo/consumidor', e graças a 'discursos' como aqueles da biologia e da economia, que devem ser encarados como

[...] regimes de saber-poder, [pois a biopolítica] elege [tais formas de verdades-poder que, enquanto científicas [possuem] a aura de indiscutibilidade e de certeza [e se referem à] gestão dos comportamentos, [sendo] o objetivo de Foucault [...] desvendar [seus] efeitos políticos 20(33-34).

Historicamente, a reflexão sobre a biopolítica aparece com Foucault, que utilizou o neologismo 'bio-política' pela primeira vez em uma palestra dada na Universidade do Estado do Rio de Janeiro (Uerj) na primeira metade dos anos 1970.

No entanto, existe também uma espécie de pré-história do conceito de 'biopolítica', que começa quando aparece a geopolítica do 'espaço vital' (Lebensraum) e o 'Estado biogeográfico'21, e que poderíamos chamar de momento 'geográfico'; prossegue quando Von Uexküll22 concebe o Estado como um organismo - com anatomia e fisiologia próprias - a ser protegido (e que poderíamos chamar de momento 'orgânico'); continua com a biopolítica entendida como estudo dos riscos e das patologias do corpo social, associada à defesa imunológica assumida pela política, e que podemos chamar de momento 'imunológico'23; e prossegue com a concepção da política norteada pelas ciências da vida (que podemos chamar de momento 'biológico'24) e que convive com as pesquisas de Foucault ${ }^{5}$; e continuará com a estratégia mais recente de compatibilizar gênero humano e ambiente ${ }^{25}$.

Entretanto, a história da biopolítica propriamente dita começa, na prática, com Foucault ${ }^{26(50)}$, quando o filósofo francês "oferece ao pensamento crítico do nosso tempo uma dimensão impreterível [intranscurabile] do exercício do poder", ou seja, quando o autor detecta uma extensão do campo de análise com a política aplicada à vida (nascimento, saúde, morte) da população e que ele concebe como uma 'estatização do biológico', isto é, entendido como o poder político sobre a vida humana (que ele chamará de 'biopoder') e que se aplica tanto à vida individual (ou corpo) como coletiva (ou espécie), podendo-se dizer que, graças às novas possibilidades de manipulação (trazidas pela biotecnociência), o biopoder se torna capaz de gerar, administrar, disciplinar e controlar os corpos, a vida e a morte. Como escreveu o próprio Foucault5(188):

[É] preciso falar de 'bio-política' para designar aquilo que faz entrar a vida e os seus mecanismos no campo dos cálculos explícitos e faz do poder-saber um agente de transformação da vida humana.

Com relação à medicina e ao controle da sociedade sobre os corpos, Foucault 26(209-210) considera que

[...] a medicina moderna é uma medicina social, cujo fundamento é uma certa tecnologia do corpo social; a medicina é uma prática social, e somente um de seus aspectos é individualista e valoriza as relações entre o médico e o paciente. [...] Sustento a hipótese que, com o capitalismo, não passamos de uma medicina coletiva para uma medicina privada, mas é o contrário que se produziu. [...] 0 controle da sociedade sobre os indivíduos não se 
efetua somente pela consciência ou pela ideologia, mas também no corpo e pelo corpo.

E sobre o poder, julga que

[...] tudo isto começou a ser descoberto [quando se percebeu] que a relação do poder [com] o indivíduo, não deve ser simplesmente essa forma de sujeição que permite ao poder tomar dos sujeitos bens, riquezas e, eventualmente, seu corpo e seu sangue, mas que o poder deve exercer-se sobre os indivíduos, uma vez que eles constituem uma espécie de entidade biológica que deve ser levada em consideração, se queremos [...] utilizar essa população como máquina para produzir [...] riquezas, bens, para produzir outros indivíduos ${ }^{27(59)}$.

E sobre o significado e a extensão do conceito de biopolítica, considera que, por biopolítica, deve-se

entender [a] maneira pela qual, a partir do século XVIII, se buscou racionalizar os problemas colocados para a prática governamental pelos fenômenos próprios de um conjunto de viventes enquanto população: saúde, higiene, natalidade, longevidade, raça27(59-60).

Por fim, sobre a estatização do biológico como característica da biopolítica da espécie humana, Foucault ${ }^{\text {19(213-216) }}$ considera que

[...] um dos fenômenos fundamentais do século $\mathrm{XIX}$ tem sido, [e] é que o poder tenha tomado a seu cargo a vida, numa perspectiva [que podemos] chamar assistencial. Trata-se [de] uma tomada de poder sobre o homem como ser vivo, de uma espécie de estatização do biológico, ou pelo menos de uma tendência em direção àquilo a que se poderia chamar a estatização do biológico [...] algo que não é mais uma anátomo-política do corpo humano, mas que chamaria uma 'biopolítica' da espécie humana.

Contudo, a partir de Foucault ${ }^{28(15-16)}$, o conceito de biopolítica vem sendo repensado
[...] no novo contexto do capitalismo cognitivo [que] produz ambíguas subjetivações, entre persistências heterônomas e espaços de autonomia, [com] uma problemática retomada do tema eugenético [e] uma abordagem incisiva a fenômenos globais [...] como o fluxo de migrantes e as guerras globais.

Nesse sentido, temos o filósofo Giorgio Agamben, que repensa a biopolítica associando-a aos conceitos de 'vida nua', 'homo sacer', 'poder soberano' e 'estado de exceção'. Para o autor, "a implicação da vida nua na esfera política constitui o núcleo originário - ainda que encoberto - do poder soberano"29(14-16) e constituiria o autêntico significado da biopolítica, pois

[a] biopolítica [é] pelo menos tão antiga quanto a exceção soberana, [devendo-se considerar que a] dupla categorial fundamental da política ocidental não é aquela amigo-inimigo, mas vida nua-existência política, zoé-bíos, exclusão-inclusão29(14-16).

Em suma, em Agamben 29(85-86), "o totalitarismo se torna um terreno privilegiado de análise da biopolítica", pois existiria um "continuum biopolítico [entre] democracia e totalitarismo". Entretanto, para o autor ${ }^{30}$, existiria também uma forma de resistência ao biopoder soberano, que o autor chama de 'biopolítica menor', que seria uma 'outra política' capaz de enfrentar o poder onde ele se exerce; isto é, "entre público e privado, corpo biológico e corpo político"; por isso, deveríamos focar "este 'no man's land' [de] duplo movimento de subjetivação e dessubjetivação" que é "aquele de uma nova política", consistente em um "retorno à vida nua, não mais como fundamento do poder, mas como forma de vida"28(90).

Nesse contexto de repensamento da biopolítica, vale a pena lembrar Roberto Esposito 31(29), que parte da constatação (já feita por Agamben) da "incerteza" que acompanharia "a categoria" de biopolítica e que a impediria de ter um significado estável, 
tornando-a objeto de debates e confrontos filosóficos e políticos sobre o futuro de nosso tempo. Para o autor, o conceito de biopolítica já teria, de fato, se instalado no debate filosófico e político, o que o teria tornado, em nosso século, um dos principais temas "de alcance global" discutido, constituindo um novo paradigma dos debates filosóficos, jurídicos e políticos, tendo se adaptado e atravessando os contextos mais variados e áreas disciplinares diferentes, tais como os estudos culturais, a estética, a hermenêutica jurídica e os discursos de gênero. Como escreveu o autor:

Em poucos anos, a noção de 'biopolítica' [...] abriu uma fase completamente nova da reflexão contemporânea. Desde que Foucault [...] repropôs e requalificou o conceito, todo o quadrante da filosofia política se viu profundamente modificado, [sendo que] o seu efeito de sentido está cada vez mais debilitado e desprovido de uma real capacidade interpretativa ${ }^{31(29)}$.

Contudo, para o autor, tal debilidade poderia ser encontrada já na filologia grega da palavra, pois "biopolítica" remeteria não tanto aos significados da palavra bios ("vida qualificada", "forma de vida"), mas à palavra zoé, isto é, à vida "na sua expressão biológica mais simples ou, quando muito, à linha de conjunção ao longo da qual o bios emerge sobre a zoé naturalizando-se também ele", razão pela qual “a ideia de biopolítica parece situar-se numa zona de dupla indiscernibilidade"31(31). Ademais, a própria palavra zoé e seu significado de "vida natural" seria de definição problemática, visto que, atualmente, graças à vigência do paradigma biotecnocientífico, "o corpo humano aparece mais desafiado, e até literalmente atravessado pela técnica"31(31). Todavia, se não existe mais uma vida "natural" que não seja também "técnica", a própria relação entre zoé e bíos deve ser pensada como estruturalmente atravessada pela técnica, algo que parece já ter sido percebido por Heidegger em seus estudos sobre a técnica e sua essência ${ }^{32}$.
Para Esposito, surge então a pergunta: se não podemos mais pensar a vida como "vida natural", por que ela seria atravessada pela técnica, e se também a política (ou biopolítica) penetra diretamente na vida, ou seja, se a própria relação entre zoé e bíos é atravessada não somente pela política, mas também pela técnica, "como supor uma relação inclusiva entre política e vida?"31(31).

Uma forma de sair dessas incertezas poderia ser tentando responder às perguntas levantadas pela vigência simultânea dos paradigmas biotecnocientífico e biopolítico, e ante o poder de fazer viver e deixar morrer (abordado por Foucault $\left.{ }^{3}\right)^{19}$, a proposta que Esposito ${ }^{31(74)}$ faz é de um 'paradigma imunitário', no qual vida (bíos) e política (nomos) constituem os dois componentes de um único e "incindível" conjunto "que só adquire sentido a partir da relação entre eles"; ou seja, a imunidade é, ao mesmo tempo, uma relação entre vida e poder e o poder de conservar a vida, razão pela qual "não existe um poder externo à vida, assim como a vida não se dá nunca fora das relações de poder", podendo-se dizer que "a imunização é uma proteção negativa da vida".

\section{Considerações finais: a relação entre bioética e biopolítica}

Se na saúde pública existe uma relação conceitual entre biotecnociência, biopolítica e bioética - como tentamos mostrar -, então temos ainda que enfrentar um desafio existencial fundamental referente ao "momento de tomada de poder decisiva do homem sobre a vida", no qual "a manipulação pelo homem" e "a manipulação sobre o homem" constituiriam a porta aberta "à manipulação ilimitada da vida"33(15), sendo que - de acordo com o sociólogo Edgar Morin 34(432) - nos encontraríamos em um impasse, visto que "é impossível deduzir uma política de uma ética" ao mesmo tempo em que "é impossível isolar uma ética [de] uma política”. 
Efetivamente, a partir da vigência da assim chamada secularização do mundo, iniciada com o humanismo renascentista, pode-se dizer que ética e política se tornaram âmbitos de estudo especializados e cada âmbito adquiriu uma relativa autonomia disciplinar, o que pode ser visto como produto da diferenciação funcional da própria sociedade, que se tornou mais complexa e na qual cada âmbito se constituiu como possível instância crítica de outros, abrindo, portanto, um possível espaço de diálogo muitas vezes polêmico. Tal situação pode ser vista como tendo a ver com aquilo entrevisto por Maliandi ${ }^{35(11,2)}$ sobre a estrutura conflitiva do ethos, que o autor define como ' $a$ priori da conflituosidade' vigente na própria sociedade, o que implicaria a difícil tarefa de tentar encontrar um "equilíbrio entre as contrapostas funções da razão" graças a uma "ética convergente que vê na razão a instância conflitiva por excelência" e que deve responder ao mesmo tempo à "exigência de evitar, resolver ou, pelo menos, regular os conflitos".

Sobre a relação entre bioética e biopolítica, ela é vista como possível porque - de acordo com Munõ $z^{36(119)}$ - a origem, os instrumentos e as aplicações da biopolítica "estão intimamente ligados ao desenvolvimento da bioética, pois a biopolítica surge mesmo como um produto da sua expansão", sendo que "esta bioética política, ou biopolítica, existe hoje em dia" e pode ser vista como

[...] a parte da bioética que transforma os problemas da interação entre as sociedades e os sistemas biológicos em decisões e ações políticas através de acordos, normas, regulamentações e leis. Em resumo, a biopolítica enfrenta os aspectos políticos e regulamentares da bioetica, encarando-a no plano [da] sociedade em gera|36(119).

No entanto, na avaliação do bioeticista Miguel Kottow ${ }^{37(159)}$, essa emergência de uma "bioética política" poderia estar indicando que a bioética se tornou "uma disciplina em risco", devido a um "excessivo academicismo" que estaria focado em "problemas pontuais e irrelevantes" quando comparados com os "grandes temas como iniquidade social, políticas públicas sanitárias, crise ecológica", que estariam, de fato, sendo assumidos ou anexados pela biopolítica, devendo-se, portanto, "impedir sua apropriação desde outros flancos, distantes da agenda específica [do] pensamento bioético".

Entretanto, a bioética pode ser vista também como uma forma de resistência ou como uma

[...] alternativa à biopolítica [que] pode em princípio mediar as questões normativas envolvidas pelas relações que se estabelecem entre bíos e zoé, entre estes e a polis [e] a techne [...] resistindo à redução biopolítica do político [a] partir de suas ferramentas próprias [e] respeitando as especificidades de cada saber envolvido, [...] estabelecendo um diálogo [com] as várias formas de saber e de poder envolvida38(531-532).

Podendo também utilizar a ferramenta da profanação

do assim chamado 'inevitável' natural estabelecido entre a biologia e a política pelo paradigma biopolítico, entendendo a profanação como um deslocamento, sem abolição daquilo que se pretende deslocar, dos dispositivos de poder ${ }^{31(191)}$.

Resumindo: o desenvolvimento de novas tecnologias trazidas pela vigência do paradigma biotecnocientífico pretende melhorar a qualidade de vida das pessoas, transformando o mundo e $o$ vivente - inclusive o humano - para adaptá-los a necessidades e desejos, em princípio legítimos, mas não necessariamente. Efetivamente, para abordar os conflitos bioéticos e biopolíticos envolvidos, não existe consenso sobre a avaliação de riscos e benefícios; podendo-se instituir e instalar uma espécie de 'biocracia' questionável e uma civilização futura, que deveria, supostamente, ser para todos, mas que pode também não ser justa e equitativa. Sem esquecer que uma das 
*Orcid (Open Researcher and Contributor ID). características importantes da inovação tecnológica é sua dimensão econômica e social, que é global. Com efeito, a partir do Pós-Segunda Guerra Mundial, fala-se em 'economia do conhecimento', que pode:

a) aprofundar as desigualdades entre países e regiões, devido à apropriação dos eventuais "benefícios da inovação pelos países ricos através de políticas de patentes e de defesa dos direitos de propriedade intelectual"14(624).

b) reforçar os "conflitos de interesses" entre "produtores de novos medicamentos

\section{Referências}

1. Di Vittorio P. Salute pubblica. In: Brandimarte R, Chiantera-Stutte P, Di Vittorio P, et al, organizadores. Lessico di biopolitica. Roma: Manifestolibri; 2006 p. 270-277.

2. La Berge A. Mission and Method. The Early-Nineteenth-Century French Public Health Movement. Cambridge: CUP; 1992.

3. Ramsey M. 2001. Mouvements anti-hygiénistas et libéralisme : vers une histoire comparée. In : Bourdelais P, organizador. Les Higiénistas, enjeux, modèles et pratiques. Paris: Belin. 2001. p. 319-340.

4. Schramm, FR, Kottow M. Principios bioéticos en salud pública: limitaciones y propuestas. Cad. Saúde Pública. 2001; 17(4): 949-956. e usuários"14(624). E consumidores, como no caso dos produtos farmacêuticos.

c) introduzir novos tipos de conflitos, bioéticos e biopolíticos, como no caso da "apropriação das biotecnologias" e o "patenteamento dos viventes", e que podem se chocar com o ideal da "ciência aberta"-.

\section{Colaboradores}

Schramm FR (0000-0001-6291-3188)* é responsável pela elaboração do manuscrito.
5. Foucault M. La volonté de savoir. Paris: Gallimard; 1976.

6. Leplège A, Fagot-Largeault A, Spira A. Santé publique. In: Canto-Sperber M, organizadora. Dictionnaire d'éthique et de philosophie morale. Paris:Presses Universitaires de France. 1996. p. 1330-1336.

7. Berlinguer G. Etica della salute. Milano: Il Saggiatore; 1994.

8. Hottois G. O paradigma bioético. Uma ética para a tecnociência. Lisboa: Salamandra; 1990.

9. Hottois G. Technoscience. In: Hottois G, Missa JN, organizadores. Nouvelle encyclopédie de bioéthique. Bruxelles: Editions De Boeck Université; 2001 p. 772. 
10. Hottois G. História da Filosofia. Da Renascença à Pós-modernidade. Lisboa: Instituto Piaget; 2003.

11. Schramm FR. Paradigma biotecnocientífico e paradigma bioético. In: Oda L, organizador. Biosafety of Transgenic Organisms in Human Health Products. Rio de Janeiro: Fiocruz; 1996. p. 109-127.

12. Schramm FR. A moralidade da biotecnociência. In: Schramm FR, Rego S, Braz M, et al., organizadores. Bioética, riscos e proteção. Rio de Janeiro: UFRJ; Fiocruz; 2005. p. 15-28.

13. Boyer R. Innovation et changement techique. In: Mesure S, Savidan P, organizadores. Le dictionnaire des sciences humaines. Paris: PUF; 2006. p. 623-625.

14. Hottois G, Missa JN, Perbal L. Introduction. In: ID. L' humain et ses préfixes. Encyclopédie du transhumanisme et du posthumanisme. Paris: Vrin; 2015. p. 7-11.

15. Anders G. L'uomo è antiquato. 2. Sulla distruzione dela vita nell'epoca dela terza rivoluzione industriale.Torino: Bollati Boringhieri. 2003. p. 3-14.

16. Harris J. Wonderwoman and Superman. The Ethics of Human Biotechnologies. Oxford: OUP; 1992.

17. Savulescu J, Persson I. Moral Enhancement 2012. [acesso em 2019 dez 20]. Disponível em: http://philosophynow.org/issues/91/Moral_Enhancement.

18. Foucault M. Il faut défendre la sociéte. Paris: Seuil; Gallimard; 1997.

19. Foucault M. Naissance de la biopolitique. In: Foucault M. Dits et Écrits II. Paris: Gallimard; Foucault M. 1994. p. 818-825.

20. Bazzicalupo L. Il governo dele vite. Biopolitica ed economia. Roma: Laterza; 2006. p. 3-5.

21. Ratzel F. "Der Lebensraum. Eine biogeograpische Studie”. In: Bücher K, Fricker K, editores. Festgaben für Albert Schäffle. Darmstadt: Wissenchaftliche Buchgesellschaft; 1901. p. 103-189.
22. Von Uexküll J. Staatsbiologie. Anatomie, Phisiologie, Pathologie des Staates. Berlin: Gebrüder Paetel Verlag; 1920.

23. Roberts M. Bio-politics. An Essay on the Physiology, Pathology and Politics of Social and Somatic Organisms. London: Dent; 1938.

24. Somit A. Biopolitics. In: Somit A, editor. Biology and Politics. Recent Explorations. The Hague: Mouton; 1976.

25. Oleskin AV, Vlavianos-Arvantis A, editores. Biopolitics. The Bio-Environment. Bio-Syllabus. Athens: Biopolitics International Organisation; 1992.

26. Foucault M. La naissance de la médecine sociale. In: Foucault M. Dits et Écrits II. Paris: Gallimard; 2001. p. 207-228.

27. Castro E. Biopolítica. In: Vocabulário de Foucault Um percurso pelos seus sistemas, conceitos e autores. Belo Horizonte: Autêntica Editora; 2009. p. 59-60.

28. Bazzicalupo L. Biopolitica. Una mappa concettuale. Roma: Carocci; 2010.

29. Agamben G. Homo sacer. O poder soberano e a vida nua I. Belo Horizonte: UFMG; 2002.

30. Agamben G. Una biopolítica minore (intervista di S. Grelet e M. Potte-Bonneville). In: Biopolítica Minore (a cura di P. Perticari). Roma: Manifestolibri; 2002. p. 191-204.

31. Esposito R. Bios: biopolítica e filosofia. Lisboa: Ed. $70 ; 2010$.

32. Heidegger M. A questão da técnica. In: Heidegger M. Ensaios e conferências, Petrópolis: Vozes, 2002. p. 11-38.

33. Morin E. Introdução ao pensamento complexo. Porto Alegre: Sulina; 2005.

34. Morin E. La méthode. 2. La vie de la vie. Paris: Seuil; 1980. 
35. Maliandi R. Ética, dilemas y convergencias: cuestiones éticas de la identidad, la globalización y la tecnología. Buenos Aires: Biblos-Universidad Nacional de Lanus; 2006.

36. Muñoz E. Biopolítica. In: Hottois G, Missa JN, organizadores. Nova enciclopédia de bioética. Lisboa: instituto Piaget; 2003. p. 119-121.
37. Kottow M. Bioética: una disciplina en riesgo. Redbioética. 2010; 1(1):159-174.

38. Schramm FR. Bioética como forma de resistência à biopolítica e ao biopoder. Bioética. 2010; 18(3):519-535.

Recebido em 21/02/2019

Aprovado em 24/09/2019

Conflito de interesses: inexistente

Suporte financeiro: não houve 